(2)

OPEN ACCESS
- Additional supplemental material is published online only. To view, please visit the journal online (http://dx.doi. org/10.1136/bjsports-2021104569).

For numbered affiliations see end of article.

\section{Correspondence to}

Dr Sebastien Racinais, Aspetar Orthopaedic and Sports

Medicine Hospital, Doha, Qatar; sebastien.racinais@aspetar.com

Accepted 26 January 2022
Check for updates

(c) Author(s) (or their employer(s)) 2022. Re-use permitted under CC BY-NC. No commercial re-use. See rights and permissions. Published by BMJ.

\section{To cite: Racinais $S$}

Havenith G, Aylwin P, et al.

Br I Sports Med Epub ahead

of print: [please include Day

Month Year]. doi:10.1136/

bjsports-2021-104569

\title{
Association between thermal responses, medical events, performance, heat acclimation and health status in male and female elite athletes during the 2019 Doha World Athletics Championships
}

\author{
Sebastien Racinais (D) ,' George Havenith, ${ }^{2}$ Polly Aylwin, ${ }^{2}$ Mohammed Ihsan (D) , 1,3 \\ Lee Taylor (1) , 4,5 Paolo Emilio Adami (D) ," 6 Maria-Carmen Adamuz (D) , \\ Marine Alhammoud, ${ }^{1}$ Juan Manuel Alonso (D) , ${ }^{1}$ Nicolas Bouscaren, ${ }^{8,9}$ \\ Sebastian Buitrago, ${ }^{10}$ Marco Cardinale (D) , ${ }^{1,11}$ Nicol van Dyk (D) , ${ }^{1,12}$ Chris J Esh, ${ }^{1,13}$ \\ Josu Gomez-Ezeiza (D) ," ${ }^{14}$ Frederic Garrandes, ${ }^{6,7}$ Louis Holtzhausen (D) ,1,15 \\ Mariem Labidi, ${ }^{1}$ Günter Lange, ${ }^{6}$ Alexander Lloyd, ${ }^{2}$ Sebastien Moussay, ${ }^{16}$ \\ Khouloud Mtibaa (D) , ${ }^{17}$ Nathan Townsend, ${ }^{18}$ Mathew G Wilson (D) ,'11 \\ Stephane Bermon (D) ${ }^{6,7}$
}

\begin{abstract}
Purpose To determine associations between thermal responses, medical events, performance, heat acclimation and health status during a World Athletics Championships in hot-humid conditions.

Methods From 305 marathon and race-walk starters, 83 completed a preparticipation questionnaire on health and acclimation. Core ( $T_{\text {core }}$; ingestible pill) and skin ( $T_{\text {skin }}$; thermal camera) temperatures were measured in-competition in 56 and 107 athletes, respectively. 70 in-race medical events were analysed retrospectively. Performance (\% personal best) and did not finish (DNF) were extracted from official results.
\end{abstract}

Results Peak $T_{\text {cre }}$ during competition reached $39.6^{\circ} \mathrm{C} \pm 0.6^{\circ} \mathrm{C}$ (maximum $41.1^{\circ} \mathrm{C}$ ). $\mathrm{T}_{\text {skin }}$ decreased from $32.2^{\circ} \mathrm{C} \pm 1.3^{\circ} \mathrm{C}$ to $31.0^{\circ} \mathrm{C} \pm 1.4^{\circ} \mathrm{C}$ during the races $(p<0.001)$. $\mathrm{T}_{\text {core }}$ was not related to DNF ( $25 \%$ of starters) or medical events $(p \geq 0.150)$, whereas $T_{\text {skin }}, T_{\text {ckin }}$ rate of decrease and $T_{\text {core }}$-to- $T_{\text {skin }}$ gradient were $(p \leq 0.029)$. A third of the athletes reported symptoms in the 10 days preceding the event, mainly insomnia, diarrhoea and stomach pain, with diarrhoea ( $9 \%$ of athletes) increasing the risk of in-race medical events ( $71 \%$ vs $17 \%$, p $<0.001$ ). Athletes (63\%) who performed 5-30 days heat acclimation before the competition: ranked better ( $18 \pm 13$ vs $28 \pm 13, p=0.009$ ), displayed a lower peak $\mathrm{T}_{\text {core }}\left(39.4^{\circ} \mathrm{C} \pm 0.4^{\circ} \mathrm{C}\right.$ vs $\left.39.8^{\circ} \mathrm{C} \pm 0.7^{\circ} \mathrm{C}, \mathrm{p}=0.044\right)$ and larger in-race decrease in $\mathrm{T}_{\text {skin }}\left(-1.4^{\circ} \mathrm{C} \pm 1.0^{\circ} \mathrm{C}\right.$ vs $-0.9^{\circ} \mathrm{C} \pm 1.2^{\circ} \mathrm{C}$, $\mathrm{p}=0.060)$, than non-acclimated athletes. Although not significant, they also showed lower DNF (19\% vs 30\%, $p=0.273$ ) and medical events ( $19 \%$ vs $32 \%, p=0.179)$. Conclusion $T_{\text {skin }} T_{\text {skin }}$ rate of decrease and $T_{\text {core }}$ - ${ }^{-}$- $T_{\text {skin }}$ gradient were important indicators of heat tolerance. While heat-acclimated athletes ranked better, recent diarrhoea represented a significant risk factor for DNF and in-race medical events.

\section{INTRODUCTION}

The globalisation of sport (eg, mega-events such as the Olympics or FIFA world cups for the first time in South-America, Asia, Africa or Middle-East) alongside global warming and congested competition calendars increasingly expose athletes to hot conditions. While an air-conditioned stadium was used during the recent 2019 athletics World Championships (WC), this is evidently not possible for endurance road-race events. Unfortunately, despite some retrospective analyses, ${ }^{12}$ there is a paucity of data on how hot ambient conditions affect the physiological responses, health and performance of elite athletes during competition.

In-competition studies report core temperatures $\geq 40.0^{\circ} \mathrm{C}$ (a threshold commonly used to determine the severity of exertional heat illness $(\mathrm{EHI}))^{3}$ in asymptomatic endurance athletes, ${ }^{4}$ with some elite athletes reaching as high as $41.5^{\circ} \mathrm{C} .^{5}$ While most athletes remain asymptomatic when competing in the heat, ${ }^{6}$ severe EHI (ie, exertional heat stroke (EHS)) is one of the two main causes of death in athletes. ${ }^{78} \mathrm{EHI}$ risk is increased in athletes with a previous EHI and/or a recent episode of illness (predominately gastrointestinal), ${ }^{6}{ }^{9}$ while heat acclimation is the most important countermeasure to protect athlete health and performance in hot ambient conditions. ${ }^{10} 11$ Despite this, only 15\% of athletes acclimated in 2015, before the Beijing athletics WC. ${ }^{12}$ The following year, educational materials were developed by the International Cycling Union and $38 \%$ of cyclists acclimated in 2016, before the cycling WC in Doha. ${ }^{13}$ World Athletics further developed similar educational material in 2019, ahead of the Doha WC (online supplemental appendix 1). However, the subsequent proportion of athletes who acclimated for this event remained to be determined; and the relationship between acclimation, previous EHI, recent illness and thermal responses, remain largely unclear, particularly within elite male and female athletes. Such data would help tailor preventive measures with greater validity to elite competition, given current measures are currently based predominately on non-elite athlete data. 


\section{Original research}

Table 1 Races and athletes characteristics

\begin{tabular}{|c|c|c|c|c|c|c|}
\hline & \multicolumn{2}{|l|}{ Marathon } & \multicolumn{2}{|l|}{ 20KRW } & \multicolumn{2}{|l|}{ 50KRW } \\
\hline & Women & Men & Women & Men & Women & Men \\
\hline \multicolumn{7}{|c|}{ Environmental conditions } \\
\hline Start time (hh:mm) & $23: 59$ & $23: 59$ & $23: 59$ & $23: 30$ & $23: 30$ & $23: 30$ \\
\hline Temperature $\left({ }^{\circ} \mathrm{C}\right)$ & $32.0 \pm 0.7$ & $29.3 \pm 0.5$ & $31.6 \pm 0.8$ & $32.7 \pm 0.2$ & $31.1 \pm 0.5$ & $31.1 \pm 0.5$ \\
\hline $\mathrm{RH}(\%)$ & $77.9 \pm 2.3$ & $46.3 \pm 1.0$ & $76.6 \pm 3.2$ & $80.6 \pm 1.1$ & $75.7 \pm 3.0$ & $75.7 \pm 3.0$ \\
\hline Wind speed $(\mathrm{m} / \mathrm{s})$ & $0.1 \pm 0.2$ & $0.4 \pm 0.5$ & $0.3 \pm 0.4$ & $1.7 \pm 0.4$ & $0.4 \pm 0.7$ & $0.4 \pm 0.7$ \\
\hline WBGT $\left({ }^{\circ} \mathrm{C}\right)$ & $29.6 \pm 0.3$ & $23.5 \pm 0.4$ & $28.9 \pm 0.5$ & $30.6 \pm 0.3$ & $28.2 \pm 0.9$ & $28.2 \pm 0.9$ \\
\hline \multicolumn{7}{|l|}{ Starters } \\
\hline $\mathrm{n}$ & 68 & 73 & 45 & 52 & 23 & 44 \\
\hline Age (years) & $30.6 \pm 5.1$ & $31.0 \pm 4.0$ & $26.9 \pm 5.9$ & $28.1 \pm 4.3$ & $29.4 \pm 5.1$ & $31.5 \pm 5.9$ \\
\hline Height $(\mathrm{cm})$ & $162 \pm 5$ & $176 \pm 7$ & $163 \pm 7$ & $179 \pm 7$ & $166 \pm 6$ & $179 \pm 7$ \\
\hline Body mass $(\mathrm{kg})$ & $48.3 \pm 4.3$ & $61.6 \pm 5.0$ & $50.4 \pm 4.3$ & $64.6 \pm 5.9$ & $52.4 \pm 6.8$ & $67.6 \pm 6.4$ \\
\hline \multicolumn{7}{|l|}{ Finishers } \\
\hline$n(\%)$ & $40(59)$ & $55(75)$ & $39(84)$ & $40(77)$ & $17(40)$ & $28(64)$ \\
\hline Age (years) & $31.0 \pm 5.7$ & $31.3 \pm 4.0$ & $27.6 \pm 5.9$ & $28.3 \pm 4.4$ & $30.0 \pm 4.6$ & $31.8 \pm 5.9$ \\
\hline Height $(\mathrm{cm})$ & $161 \pm 6$ & $176 \pm 7$ & $162 \pm 7$ & $178 \pm 8$ & $166 \pm 5$ & $182 \pm 6$ \\
\hline Body mass $(\mathrm{kg})$ & $47.9 \pm 5.3$ & $61.6 \pm 5.0$ & $49.9 \pm 4.5$ & $64.9 \pm 6.2$ & $52.7 \pm 7.3$ & $70.0 \pm 6.2$ \\
\hline$n(\%)$ & $28(41)$ & $18(25)$ & $3(7)$ & $7(13)$ & $6(26)$ & $13(30)$ \\
\hline Age (years) & $30.0 \pm 4.2$ & $30.1 \pm 3.8$ & $23.5 \pm 5.9$ & $28.6 \pm 3.3$ & $27.8 \pm 6.3$ & $31.3 \pm 5.8$ \\
\hline Height $(\mathrm{cm})$ & $163 \pm 5$ & N/A & $165 \pm 9$ & $184 \pm 2$ & $166 \pm 11$ & $174 \pm 6$ \\
\hline Body mass $(\mathrm{kg})$ & $48.8 \pm 2.6$ & $\mathrm{~N} / \mathrm{A}$ & $53.3 \pm 1.5$ & $63.9 \pm 7.3$ & $51.5 \pm 7.8$ & $64.4 \pm 5.8$ \\
\hline \multicolumn{7}{|l|}{ Medical events } \\
\hline $\mathrm{n}(\%)$ & $32(47)$ & $12(16)$ & $6(13)$ & $3(6)$ & $6(26)$ & $11(25)$ \\
\hline Age (years) & $29.5 \pm 5.3$ & $30.8 \pm 3.9$ & $28.0 \pm 7.7$ & $32.8 \pm 4.2$ & $29.2 \pm 5.8$ & $31.1 \pm 7.8$ \\
\hline Height $(\mathrm{cm})$ & $162 \pm 6$ & $\mathrm{~N} / \mathrm{A}$ & $164 \pm 6$ & $185 \pm N / A$ & $168 \pm 7$ & $181 \pm 6$ \\
\hline Body mass $(\mathrm{kg})$ & $49.1 \pm 3.3$ & N/A & $47.4 \pm 4.0$ & $70 \pm N / A$ & $55.3 \pm 6.7$ & $67.1 \pm 6.5$ \\
\hline \multicolumn{7}{|l|}{ Results } \\
\hline Time (\%PB) & $115 \pm 5$ & $106 \pm 4$ & $112 \pm 4$ & $119 \pm 6$ & $111 \pm 4$ & $115 \pm 5$ \\
\hline
\end{tabular}

Values in mean \pm SD.

DNF, did not finish; KRW, km race-walk; N/A, not available; \%PB, percentage of personal best; RH, relative humidity; WBGT, wet-bulb globe temperature.

The current study aimed to initially determine athletes' thermal responses during the male and female road-races of the 2019 Doha WC, alongside ascertaining their preparation strategies and health-status before the event (eg, acclimation strategy, recent illness, etc). The overall objective was to establish any differences and/or association between these factors and the risk of did not finish (DNF) or suffering an in-race medical event.

\section{METHODS}

Design

This cross-sectional study included: (i) a pre-race questionnaire; (ii) an in-race monitoring of core $\left(\mathrm{T}_{\text {core }}\right)$ and/or skin $\left(\mathrm{T}_{\text {skin }}\right)$ temperatures and (iii) a retrospective analysis of the medical events and performance. Athletes were free to participate in any measures of this cross-sectional study irrespective of completing other measures.

The study was conducted during the road-races of the Doha WC (27 September-6 October 2019), held in hot and humid environmental conditions (table 1). The marathons, $20 \mathrm{~km}$ $(20 \mathrm{KRW})$ and $50 \mathrm{~km}(50 \mathrm{KRW})$ race-walks were completed on $7 \mathrm{~km}, 1 \mathrm{~km}$ and $2 \mathrm{~km}$ loop laps, respectively. All road-races were held during the night with starting times between 23:30 and midnight (table 1).

\section{Participants}

All athletes competing in the marathons, 20KRW and 50KRW $(n=305)$ could participate. They were informed of the project through their national federations, coaches or support staff. $\mathrm{T}_{\text {skin }}(\mathrm{n}=107$ athletes $)$ and $\mathrm{T}_{\text {core }}(\mathrm{n}=56$ athletes $)$ were measured, with 83 athletes completing the prerace questionnaire. The 80 athletes visiting the medical facilities were classified as per the International Institute of Race Medicine classification (by their attending physician and the WC chief medical officer) and 10 of them were not included for final analyses ( 8 presented for injury plus 2 were discharged without symptoms); leaving 70 athletes with in-race medical events (ie, related to illness) to be analysed. The sample sizes for the different comparisons are presented in table 2 .

Table 2 Number of participants for the different measures

\begin{tabular}{|c|c|c|c|c|}
\hline & & \multirow{2}{*}{$\frac{\text { Core }}{\text { Temperature }}$} & \multirow{2}{*}{$\frac{\text { Skin }}{\text { Temperature }}$} & \multirow{2}{*}{$\begin{array}{l}\text { Core to skin } \\
\text { Gradient }\end{array}$} \\
\hline & & & & \\
\hline All & & 56 & 107 & 50 \\
\hline \multirow[t]{2}{*}{ Finisher } & Did not finish & 12 & 21 & 8 \\
\hline & Finisher & 38 & 82 & 38 \\
\hline \multirow[t]{2}{*}{ In-race illness } & Yes & 9 & 43 & 8 \\
\hline & No & 47 & 64 & 42 \\
\hline \multirow[t]{2}{*}{ Recent illness } & Diarrhoea & 6 & 7 & 6 \\
\hline & No diarrhoea & 37 & 51 & 32 \\
\hline \multirow[t]{2}{*}{ Acclimation } & Yes & 29 & 35 & 25 \\
\hline & No & 17 & 28 & 16 \\
\hline
\end{tabular}




\section{Measures}

\section{Core temperature}

$\mathrm{T}_{\text {core }}$ (precision $0.1^{\circ} \mathrm{C}$; sampled every $30 \mathrm{~s}$ ) was continuously recorded using e-Celsius ingestible capsules (BodyCap, Caen, France). Athletes ingested the capsule 4-6hours prior to their event, encouraging transit through the stomach into the gastrointestinal tract while minimising pill-loss through defaecation. ${ }^{5}$ Peak $\mathrm{T}_{\text {core }}$ (consistently observed at the end of race) alongside $\mathrm{T}_{\text {skin }}$ during the last lap, were used to calculate the $\mathrm{T}_{\text {core }}-$ to- $\mathrm{T}_{\text {skin }}$ gradient at the end of the event. For DNF, the end of their event was determined as the point of race abandonment.

\section{Nude skin temperature}

$\mathrm{T}_{\text {skin }}$ (average of the frontal, lateral and posterior nude areas) was recorded during the first and last lap of the races via thermal cameras (FLIR A6750sc and FLIR T1030sc). ${ }^{14}$ Details are provided in online supplemental appendix 2 .

\section{Performance}

Ranking and finishing times were extracted from official race results, with the latter expressed as a percentage of the athlete personal best at the time of the WC (PB; obtained from World Athletics' official starting list).

\section{Questionnaire}

Participants completed a preparticipation questionnaire (available in 12 different languages; online supplemental appendix 2) similar to the questionnaire developed and used before the 2015 athletic $\mathrm{WC}^{12}$ and the 2016 cycling WC. ${ }^{13}$ The questionnaire surveyed: (i) demographic data such as sex; (ii) EHI history; (iii) recent illness during the 10 days preceding the event and (iv) heat-acclimation strategy.

\section{Environmental conditions}

Measured every $30 \mathrm{~min}$ using a heat stress metre (Kestrel 4400, Boothwyn, Pennsylvania, USA) mounted on a tripod $\sim 1.5 \mathrm{~m}$ above the floor, $\sim 4 \mathrm{~m}$ from the course (near the start/finish line).

\section{Statistical analyses}

Data were analysed in Wizard (V.1.9.41, Evan Miller). The thermal responses (eg, $\mathrm{T}_{\text {core, }} \mathrm{T}_{\text {skin }}$ or $\mathrm{T}_{\text {core }}$-to- $\mathrm{T}_{\text {skin }}$ gradient) were analysed through two-tailed t-tests when comparing two categories (eg, sex, or yes/no for previous history of EHI, recent illness or acclimation) and analysis of variance when comparing multiple categories (eg, event). The categorical variables (eg, number of medical events vs sex or yes/no for previous history of EHI, recent illness or acclimation) were compared using $\chi^{2}$ tests. Sidak adjustments were applied for multiple comparisons. Twotailed alpha was set at $\leq 0.05$. Data are presented as mean \pm SD.

\section{RESULTS}

From 305 starters, 219 athletes finished their race (72\%), 75 DNF (25\%) and 11 were disqualified (during race-walks). No differences in age, height or body mass were observed between finishers and DNF (all $\mathrm{p} \geq 0.337$, table 1 ). Finishers completed their event $12 \% \pm 7 \%$ slower than their PB (table 1 ).

\section{Thermal responses}

Peak $\mathrm{T}$ was $39.6^{\circ} \mathrm{C} \pm 0.6^{\circ} \mathrm{C}$ (independent of event, $\left.\mathrm{p}=0.499\right) .{ }^{15}$ The $\mathrm{T}_{\text {core }}$ of the DNF athletes $(\mathrm{p}=0.150)$, or of athletes with a medical event $(p=0.576)$, were not different from other athletes (figure 1). Conversely, DNF finished their race with a higher $\mathrm{T}_{\text {skin }}$ than finishers $\mathrm{T}_{\text {skin }}$ during their final lap $\left(32.0^{\circ} \mathrm{C} \pm 1.4^{\circ} \mathrm{C}\right.$ vs $30.6^{\circ} \mathrm{C} \pm 1.2^{\circ} \mathrm{C}, \mathrm{p}<0.001$, figure 1$)$. The absolute $\mathrm{T}_{\text {skin }}$ decrease during the entire race $\left(-0.1^{\circ} \mathrm{C} \pm 1.1^{\circ} \mathrm{C}\right.$ vs $-1.5^{\circ} \mathrm{C} \pm 0.9^{\circ} \mathrm{C}$, $\mathrm{p}<0.001)$ and the rate of $\mathrm{T}_{\text {skin }}$ decrease per kilometre $\left(0.00^{\circ} \mathrm{C} /\right.$ $\mathrm{km} \pm 0.07^{\circ} \mathrm{C} / \mathrm{km}$ vs $\left.-0.05^{\circ} \mathrm{C} / \mathrm{km} \pm 0.04^{\circ} \mathrm{C} / \mathrm{km}, \mathrm{p}<0.001\right)$ were lower in DNF than in finishers. Similarly, athletes with a medical event had a lower $\mathrm{T}_{\text {skin }}$ rate of decrease per kilometre than others $\left(-0.03^{\circ} \mathrm{C} / \mathrm{km} \pm 0.05^{\circ} \mathrm{C} / \mathrm{km}\right.$ vs $-0.06^{\circ} \mathrm{C} / \mathrm{km} \pm 0.06^{\circ} \mathrm{C} / \mathrm{km}$, $\mathrm{p}=0.011)$.

While potentially affected by early withdrawal, the $\mathrm{T}_{\text {core }}{ }^{-}$ to- $\mathrm{T}_{\text {skin }}$ gradient was lower in $\mathrm{DNF}$ athletes than in finishers $\left(6.7^{\circ} \mathrm{C} \pm 1.2^{\circ} \mathrm{C}\right.$ vs $9.4^{\circ} \mathrm{C} \pm 1.5^{\circ} \mathrm{C}, \mathrm{p}<0.001$; figure 1$)$. Athletes with a medical event had a lower $\mathrm{T}_{\text {core }}-$ to- $\mathrm{T}_{\text {skin }}$ gradient than others $\left(7.6^{\circ} \mathrm{C} \pm 1.5^{\circ} \mathrm{C}\right.$ vs $\left.9.0^{\circ} \mathrm{C} \pm 1.7^{\circ} \mathrm{C}, \mathrm{p}=0.029\right)$.

\section{Medical events}

Fifty-seven per cent $(n=43)$ in DNF vs $17 \% \quad(n=37)$ in finishers $(p<0.001)$ visited the medical facility including: 20 exercise-associated collapse; 16 exercise-associated muscle cramps; 16 heat-exhaustion; 12 gastrointestinal disturbances;
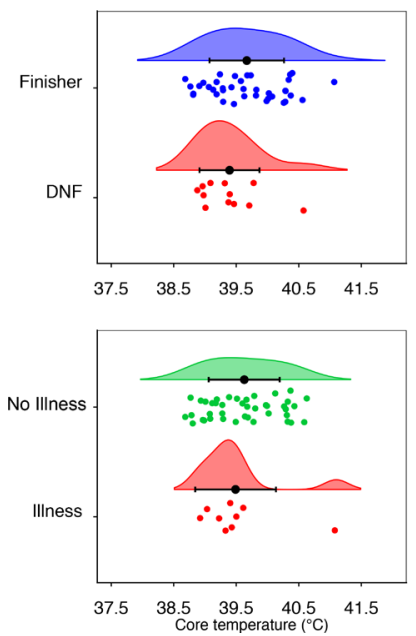
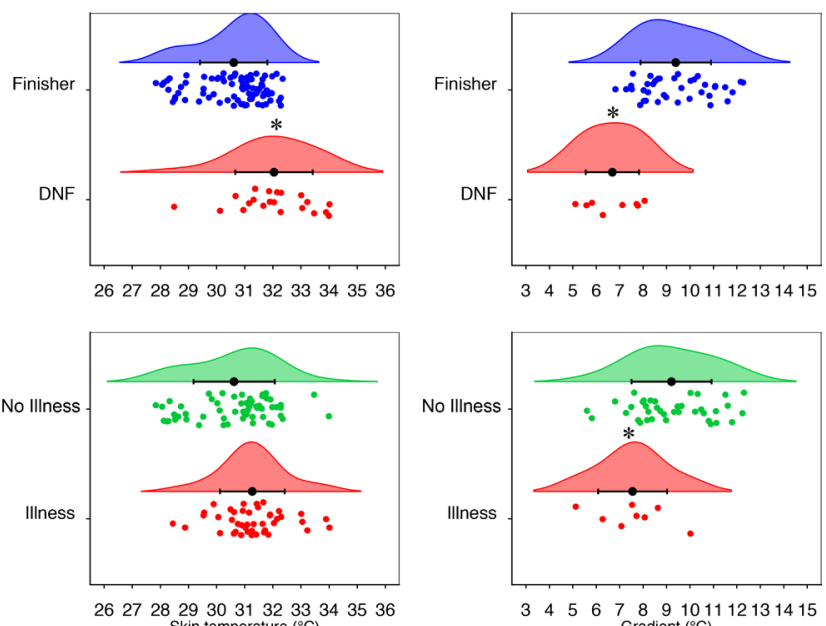

Skin temperature $\left({ }^{\circ} \mathrm{C}\right)$

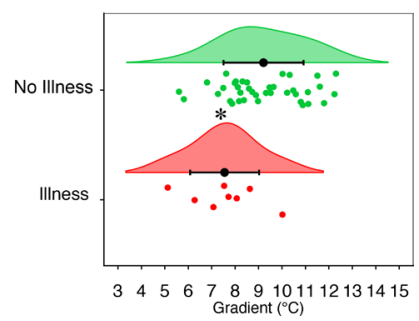

Figure 1 Rain clouds ${ }^{30}$ of the core temperature, skin temperature and core to skin temperature gradient at the end of the races. Mean $\pm S D$ and individual values for the did not finish (DNF)/finishers (top panels), and for the athletes being/not being admitted to the medical facility for an in-race illness (bottom panels); ${ }^{*} \mathrm{p}<0.05$. 
1 heat-exhaustion with exercise-associated collapse and 1 heatexhaustion combined with gastrointestinal disturbances. No EHS was diagnosed in the medical tent. One athlete was transferred to a hospital emergency ward (possible panic attack) and was discharged some hours later.

Average systolic/diastolic blood pressures were $115 \pm 13 / 69 \pm 13 \mathrm{~mm} \mathrm{Hg}$ at admission, with an extreme value of $73 / 40 \mathrm{~mm} \mathrm{Hg}$ in a female marathoner diagnosed with hypotensive collapse and dehydration (discharged after intravenous fluid replacement and leg elevation). Most athletes were conscious $(100 \%)$ and alert (94\%), but required assistance (wheelchair $(n=33)$, stretcher $(n=12)$, buggy $(n=7)$, ambulance $(n=3)$; while 17 walked-in).

\section{Previous EHI}

Of the survey responders, $61 \%$ had previously experienced a variety of EHI symptoms while training/competing in the heat (eg, cramping, headache, nausea) and $17 \%$ of all responders declared to have been previously diagnosed with EHI. Cramping was the most common symptom previously experienced $(26.5 \%)$ as well as the most common complaint at the medical facility during the WC $(9 \%, \mathrm{n}=27)$.

The DNF subsample was not associated with a history of EHI symptoms $(p=0.459)$ or EHI diagnosis $(p=0.860)$. The peak $\mathrm{T}_{\text {core }}$ was also similar between athletes with a history of EHI and others $\left(39.6^{\circ} \mathrm{C} \pm 0.6^{\circ} \mathrm{C}\right.$ vs $\left.39.6^{\circ} \mathrm{C} \pm 0.6^{\circ} \mathrm{C}, \mathrm{p}=0.968\right)$. However, in-race medical events were higher in athletes with a previous history of EHI symptoms (16/51 or $31 \%$ vs $4 / 32$ or $13 \%, \mathrm{p}=0.050)$.

\section{Recent illness}

Of the responders, 33\% declared symptoms of illness during the 10 days preceding their event (independent of event; $\mathrm{p}=0.116$ ) (figure 2). Overall, this was not associated with DNF $(\mathrm{p}=0.688)$ or in-race medical events $(p=0.385)$. The most common symptom was insomnia (figure 2 ). Only three athletes reporting insomnia had their $\mathrm{T}_{\text {core }}$ monitored (peak $\mathrm{T}_{\text {core }} 39.5^{\circ} \mathrm{C}, 40.3^{\circ} \mathrm{C}$ and $40.7^{\circ} \mathrm{C}$ ).

The second most commonly reported symptom, diarrhoea ( $9 \%$ of all athletes) was more prevalent in the athletes suffering an in-race medical event than in others athletes $(5 / 17$ or $29 \%$ vs $2 / 60$ or $3 \%, \mathrm{p}<0.001$ ). Concerningly, $71 \%$ (ie, $5 / 7$ ) of athletes reporting a diarrhoea episode in the 10 days preceding the competition suffered an in-race medical event vs $17 \%$ (ie, 12/70) of the athletes not reporting recent diarrhoea $(\mathrm{p}<0.001$, figure 2$)$. Moreover, although not statistically significant $(p=0.167), 43 \%$ of the athletes with recent diarrhoea DNF (ie, 3/7) vs only $20 \%$ (ie, 13/65) of the other athletes. The final $\mathrm{T}_{\text {core }}\left(39.8^{\circ} \mathrm{C} \pm 0.8^{\circ} \mathrm{C}\right.$ vs $\left.39.6^{\circ} \mathrm{C} \pm 0.6^{\circ} \mathrm{C}, \mathrm{p}=0.549\right)$ and $\mathrm{T}_{\text {skin }}\left(31.1^{\circ} \mathrm{C} \pm 1.8^{\circ} \mathrm{C}\right.$ vs $\left.30.8^{\circ} \mathrm{C} \pm 1.4^{\circ} \mathrm{C}, \mathrm{p}=0.734\right)$ were not statistically different between athletes with and without recent diarrhoea.

\section{Heat acclimation}

Most athletes (80\%, independently of event, $p=0.596)$ had some form of heat exposure before the current WC. The proportion of athletes with a dedicated 5-30 days heat preparation period was $63 \%$, depending on event $(\mathrm{p}=0.049)$, with a lower prevalence in marathon than $50 \mathrm{KRW}(48 \%$ vs $82 \%, \mathrm{p}=0.028$; $20 \mathrm{KRW} 63 \%$, figure 3 ). Within the athletes training in the heat, the methods also differed between events $(p=0.049)$ with $83 \%$ of marathon runners relying on natural outdoor heat only, whereas $33 \%$ of the $50 \mathrm{KRW}$ and $55 \%$ of the $20 \mathrm{KRW}$ trained in a hot room (figure 3). Similarly, the proportion of athletes incorporating passive heat exposure during their taper was lower in marathoners $(21 \%)$ than in race-walkers $(55 \%)(p=0.010)$.

Athletes who acclimated had a non-significantly lower $\mathrm{T}_{\text {core }}$ at the start $\left(-0.2^{\circ} \mathrm{C}, \mathrm{p}=0.095\right)$ and a significantly lower peak $\mathrm{T}_{\text {core }}\left(-0.4^{\circ} \mathrm{C}, \mathrm{p}=0.044\right)$ compared with athletes who did not acclimate (figure 3). Athletes who acclimated had a nonsignificantly higher $\mathrm{T}_{\text {skin }}$ during the first lap $\left(+0.7^{\circ} \mathrm{C}, \mathrm{p}=0.060\right)$ that was compensated by a larger decrease during the race $\left(-1.4^{\circ} \mathrm{C} \pm 1.0^{\circ} \mathrm{C}\right.$ vs $\left.-0.9^{\circ} \mathrm{C} \pm 1.2^{\circ} \mathrm{C}, \mathrm{p}=0.060\right)$ and no differences in final $\mathrm{T}_{\text {skin }}(\mathrm{p}=0.646)$. Athletes who acclimated ranked better during their race $(18 \pm 13$ vs $28 \pm 13, \mathrm{p}=0.009)$, but the relative performance was not different $(112.6 \% \pm 5.1 \% \mathrm{~PB}$ vs $113.3 \% \pm 7.3 \% \mathrm{~PB}, \mathrm{p}=0.643)$. Lastly, although not statistically significant $(p \geq 0.179), 30 \%(n=9 / 30)$ and $32 \%(n=10 / 31)$ of the athletes who did not acclimate were respectively DNF or in-race medical event, versus only $19 \%(n=9 / 47$ and $n=10 / 52)$ of the athletes who acclimated (figure 3).

\section{Illness in \% of all athletes (\% illness)}

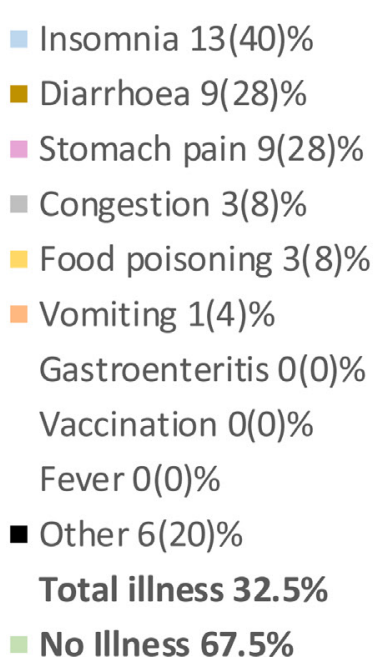
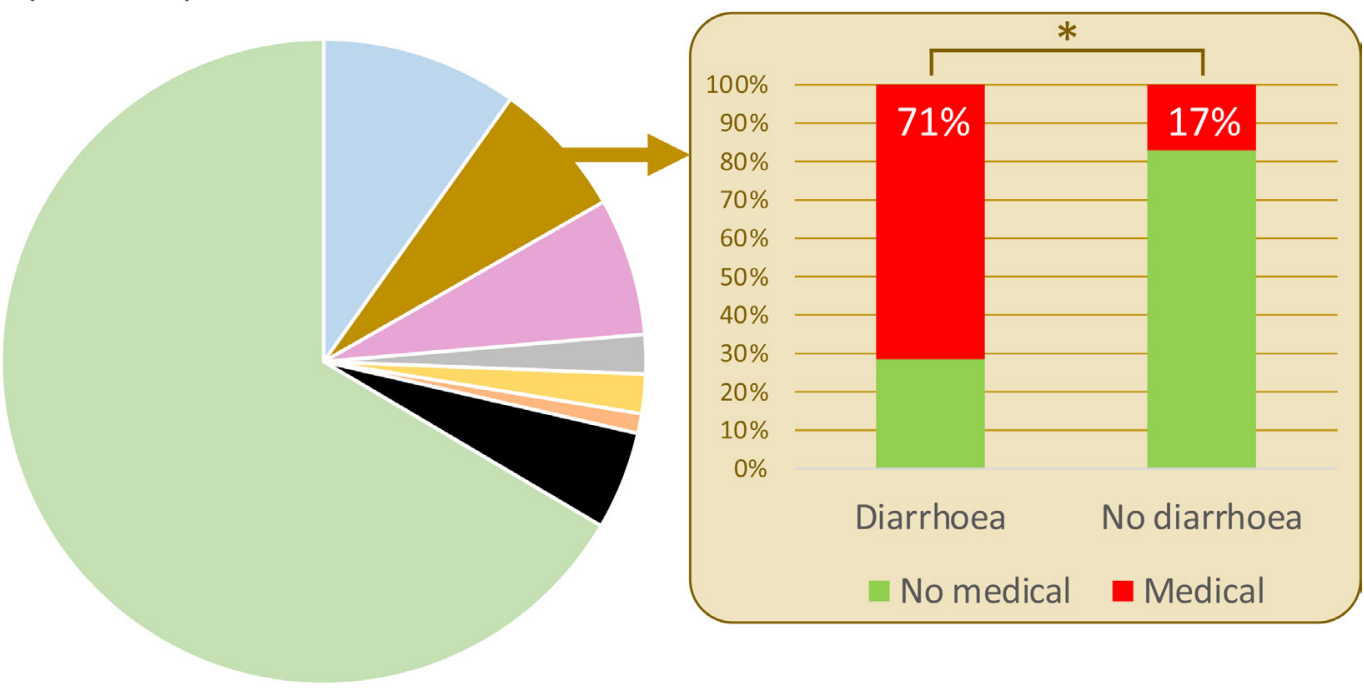

Figure 2 Recent illness (in the 10 days preceding the World Championships). * $\mathrm{P}<0.05$. 


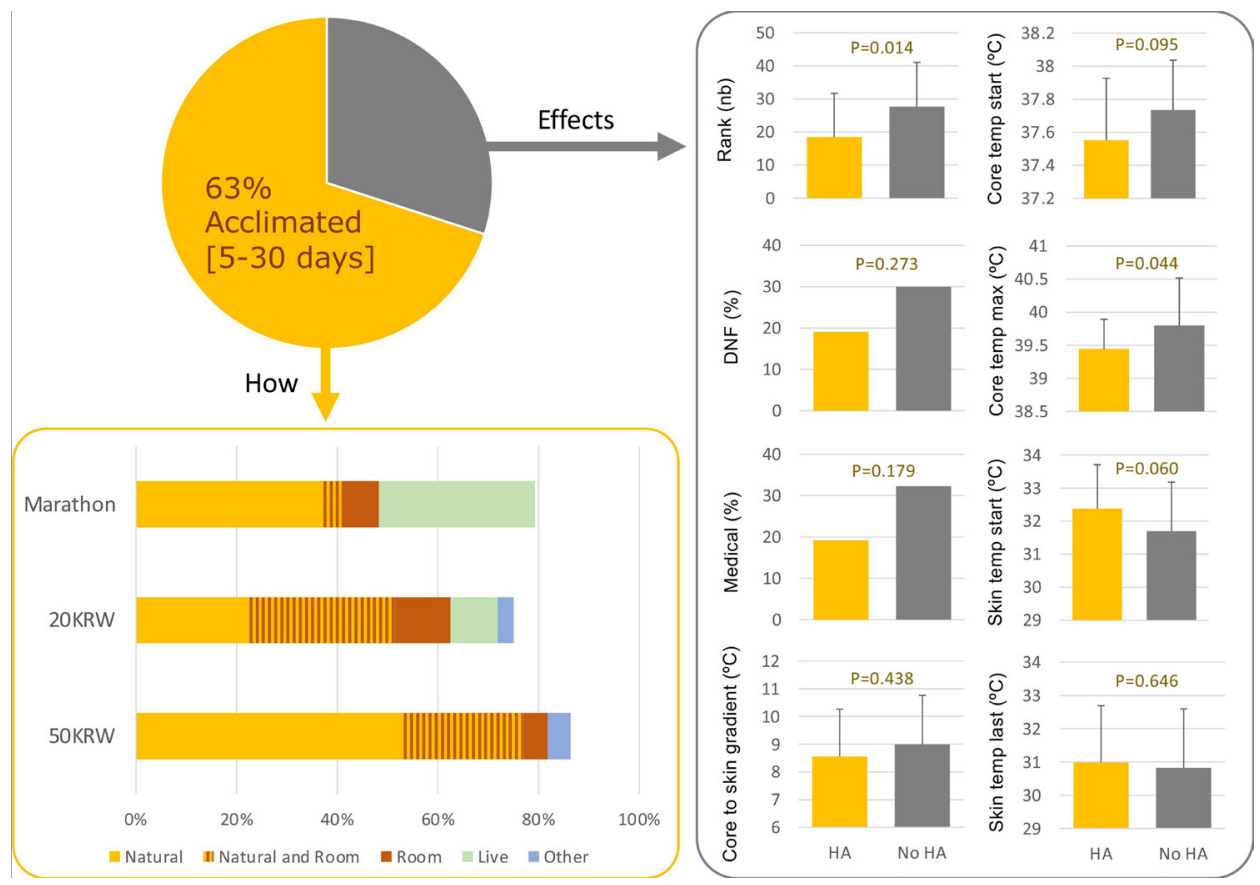

Figure 3 Proportion of athletes who acclimated for 5-30 days ahead of the World Championships (top left), main methods for acclimation (bottom left) and effects on other variables (right panel). DNF, did not finish; HA, heat acclimation; Live, athletes declaring to live in a hot country; Medical, admittance to the medical facility for in-race illness; temp, temperature; $20 \mathrm{KRW}, 20 \mathrm{~km}$ race-walk; $50 \mathrm{KRW}, 50 \mathrm{~km}$ race-walk.

Sex

There were no differences between sexes regarding whether athletes had some form of heat exposure ( $78 \%$ vs $81 \%, \mathrm{p}=0.731)$, a 5-30 days acclimation period $(56 \%$ vs $68 \%, \mathrm{p}=0.242)$, a recent illness (38\% vs 29\%, p=0.426), a previous history of $\mathrm{EHI}$ $(12 \%$ vs $21 \%, p=0.307)$ or DNF $(p=0.355)$. Women had faster relative performance than men in the $20 \mathrm{KRW}(\mathrm{p}<0.001)$ and $50 \mathrm{KRW}(\mathrm{p}=0.006)$, but a slower relative performance on the marathon $(\mathrm{p}<0.001$, likely related to the difference in environmental conditions, table 1$)$.

The proportion of women with an in-race medical event was higher than men $(32 \%$ vs $17 \%, \mathrm{p}<0.001)$. This difference was however likely due to the different environmental conditions during the women and men marathons (table 1) as there was no effect of sex on the prevalence of in-race medical event during race-walks $(p=0.597)$, where environmental conditions were similar.

The peak $\mathrm{T}_{\text {core }}$ was not different between women and men $\left(39.5^{\circ} \mathrm{C} \pm 0.6^{\circ} \mathrm{C}\right.$ vs $\left.39.6^{\circ} \mathrm{C} \pm 0.6^{\circ} \mathrm{C}, \mathrm{p}=0.544\right)$. The final $\mathrm{T}_{\text {skin }}$ was higher in women than men $\left(31.5^{\circ} \mathrm{C} \pm 0.8^{\circ} \mathrm{C}\right.$ vs $30.4^{\circ} \mathrm{C} \pm 1.6^{\circ} \mathrm{C}$, $\mathrm{p}<0.001)$. Whereas this may be largely related to large differences during the marathons $\left(31.5^{\circ} \mathrm{C} \pm 1.2^{\circ} \mathrm{C}\right.$ vs $29.0^{\circ} \mathrm{C} \pm 1.1^{\circ} \mathrm{C}$, $\mathrm{p}<0.001$ ), the final $\mathrm{T}_{\text {skin }}$ of the women was also marginally higher than the men during the race walk $\left(31.5^{\circ} \mathrm{C} \pm 0.4^{\circ} \mathrm{C}\right.$ vs $\left.31.0^{\circ} \mathrm{C} \pm 1.4^{\circ} \mathrm{C}, \mathrm{p}=0.145\right)$. The $\mathrm{T}_{\text {core }}$-to- $\mathrm{T}_{\text {skin }}$ gradient was significantly lower in women than men $\left(7.8^{\circ} \mathrm{C} \pm 0.9^{\circ} \mathrm{C}\right.$ vs $9.3^{\circ} \mathrm{C} \pm 1.9^{\circ} \mathrm{C}$, $\mathrm{p}=0.005)$, but only during the marathon.

\section{DISCUSSION}

The current project aimed to determine the athletes' thermal responses and preparedness for a WC held in hot-humid conditions. First, athletes commonly reach $\mathrm{T}_{\text {core }}$ above $40.0^{\circ} \mathrm{C}$ with the maximum $\mathrm{T}_{\text {core }}$ observed during the $20 \mathrm{KRW}\left(41.1^{\circ} \mathrm{C}\right)$; confirming that the highest $\mathrm{T}_{\text {core }}$ are not always reached during the longest events. ${ }^{5}$
Second, there were 70 medical encounters related to in-race illness. An increase in environmental heat stress has been reported to increase the number of heat-related illness cases in international marathon and race-walk events. ${ }^{2}$ Given that up to 13 athletes required a wheelchair during a single event (women's marathon, table 1), the current study suggests that event organisers should consider a 1:5 wheelchairs to starters ratio for WC road-races in hot and humid conditions.

Third, numerous athletes $(26.5 \%)$ reported to have previously experienced cramping when exercising in the heat. This proportion is similar to that reported in elite long-distance athletes $(25.5 \%)^{12}$ and cyclists $(26 \%) .{ }^{13}$ Cramping was also the most frequently observed complaint at the medical facility (9\%). While most muscle cramps are attributed to premature muscle fatigue ${ }^{16}$ the current observation support that exercising in the heat may still promote cramping in some athletes. ${ }^{17}$

Fourth, there was no consistent effect of sex on relative performance, refuting the common belief that women are at a greater disadvantage than men when competing in the heat. Indeed, most differences arise from anthropometric differences and sex per se does not significantly affect thermal responses, except during intense exercise in dry heat allowing full sweat evaporation. ${ }^{18-20}$ Thus, in the humid conditions of the current WC, where sweat rates exceeded the maximal evaporation rate possible, the effect of sex on performance was likely trivial. ${ }^{21}$ Moreover, a retrospective analysis of 7 international athletic championships revealed 132 cases of heat illnesses, but did not observe sex differences. ${ }^{2}$ No effects of sex were also observed for heat-related illness in elite cycling ${ }^{13}$ and beach volleyball. ${ }^{6}$ Yet, this latter study reported that $60 \%$ of the heat-related medical time-outs were among women, ${ }^{6}$ and the current study also showed a higher proportion of women than men suffered a medical event (although due to the higher ambient temperatures during the women's). Also, $\mathrm{T}_{\text {core }}>41^{\circ} \mathrm{C}$ were only observed in female athletes both during the 2016 cycling $\mathrm{WC}^{5}$ and the 
current athletic WC. Overall, there may be an effect of sex on the sensitivity to heat in elite athletes, but it appears marginal as compared with the large effects of exercise heat stress per se.

Fifth, despite an elevated 41\% DNF during the women's marathon, a Spearman's rank correlation showed that the overall DNF proportion did not differ from previous WC $(p=0.206$, based on public data since 1983) (online supplemental appendix $3)$. However, as compared with the standing World record at the time of each WC (ie, to account for the evolution of performance across three decades), completion time was relatively slower at the 2019 WC than previous WC $(\mathrm{p}<0.001$, online supplemental appendix 3). Therefore, the main performance consequence of heat in elite athletes was a reduction in speed (ie, a lower absolute intensity), likely due to the attempted maintenance of the same relative intensity (eg, heart rate). ${ }^{22}$

Sixth, the fact that $63 \%$ of athletes heat-acclimated for 5-30 days indicates increased awareness of, as well as increased number of athletes adopting heat acclimation. Indeed, only $15 \%$ and $38 \%$ of the athletes undertook heat acclimation prior to the 2015 athletic $\mathrm{WC}^{12}$ and 2016 cycling WC, ${ }^{13}$ respectively. This increase likely reflects the efficacy of educational material produced by the International Cycling Union (UCI) ahead of the 2016 cycling WC and then by the International Association of Athletics Federations (IAAF) ahead of the 2019 athletic WC (online supplemental appendix 1). While marathoners were less inclined to have a dedicated heat acclimation block, this could be partially explained by the fact that more marathoners than race-walkers declared living in hot countries, and thus may have considered it not necessary to perform specific acclimation (figure 3).

Seventh, a third of the athletes declared symptoms of illness during the 10 days preceding their event. This is a worrying increase compared with the $13 \%$ of athletes reporting symptoms during the 4 weeks preceding the 2015 athletics' WC, ${ }^{23}$ or the $22 \%$ of cyclists reporting symptoms during the 10 days preceding the 2016 cycling WC (ie, same questionnaire as the current study). ${ }^{13}$

\section{Risk factors and countermeasures}

The leading objective of the current project was to determine the associations between the above responses and the risk of DNF or medical event. For example, it has been shown that $19 \%$ of amateur runners experienced illness symptoms in the 8-12 days preceding a long distance endurance event, increasing their risk of DNF $\sim$ twofold. ${ }^{24}$ In the current study, there was no overall relationship between DNF or in-race illness and a recent symptom (the most common symptom being insomnia possibly due to the races being held close to midnight). However, the second most common symptom, diarrhoea, was a major risk factor for in-race medical events (figure 2). This confirms a recent retrospective analysis of beach volleyball WC and world-tour events suggesting that a recent episode of diarrhoea increased the severity of heat-related medical time-out. ${ }^{6}$ Considering the changes in gut microbiota and gastrointestinal symptoms affecting thermoregulation when exercising in the heat, ${ }^{25}$ it is likely that starting a race in a hot and humid environment with less than optimal gastrointestinal health/function may impose increased thermoregulatory challenges. The deleterious effect of diarrhoea on the capacity to exercise in the heat is likely multifactorial (including hydration and electrolyte level) as final $\mathrm{T}_{\text {core }}\left(39.8^{\circ} \mathrm{C} \pm 0.8^{\circ} \mathrm{C}\right.$ vs $\left.39.6^{\circ} \mathrm{C} \pm 0.6^{\circ} \mathrm{C}, \mathrm{p}=0.549\right)$ and $\mathrm{T}_{\text {skin }}\left(31.1^{\circ} \mathrm{C} \pm 1.8^{\circ} \mathrm{C}\right.$ vs $\left.30.8^{\circ} \mathrm{C} \pm 1.4^{\circ} \mathrm{C}, \mathrm{p}=0.734\right)$ were not statistically different between athletes with and without recent diarrhoea. The current data also confirm that EHI history is a risk factor for experiencing a medical event when competing in the heat, ${ }^{9}$ but to a lower extent than a recent diarrhoea.

Heat acclimation is the most important preventative countermeasure to protect athlete health and performance in hot ambient conditions. ${ }^{10} 11$ In line with laboratory data showing that heat acclimation lowers $\mathrm{T}_{\text {core }}$ for a given exercise load (and sometimes at rest), ${ }^{26}$ the current data show a non-significant lower $\mathrm{T}_{\text {core }}$ at the start and a significantly lower peak $\mathrm{T}_{\text {core }}$ in competition (figure 3). Importantly, athletes who acclimated had a better finishing position (figure 3), although it may reflect a general tendency for the best athletes to better prepare rather than a different relative performance. It is also noteworthy that $>30 \%$ of non-acclimated athletes DNF and/or suffered an in-race medical event, versus only $19 \%$ of the acclimated athletes (figure 3).

In the effort of determining the associations between the various physiological and pathophysiological responses to competing in the heat, a new technology was also deployed (online supplemental appendix 2) to provide the first in-race $\mathrm{T}_{\text {skin }}$ measures ever obtained. ${ }^{14}$ Although it is important to reaffirm that $\mathrm{T}_{\text {core }}$ is the clinical criterion to diagnose EHS and associated risk of organ damage, the current data showed that higher $\mathrm{T}_{\text {skin }}$ and a reduced $\mathrm{T}_{\text {core }}-$ to- $\mathrm{T}_{\text {skin }}$ gradient are important indicators of the athlete's ability to cope with heat stress, finish the race and/ or potentially require medical attention (figure 1). This confirms for the first time, during outdoor elite competition, that the $\mathrm{T}_{\text {core }}$ to- $\mathrm{T}_{\text {skin }}$ gradient is a central component of exercise capacity in the heat. ${ }^{27}$ Indeed, a lower gradient requires a higher skin blood

Summary box

What is already known on this topic?

- Athletes commonly reach core temperatures $>40.0^{\circ} \mathrm{C}$ when competing in the heat.

- The risk factors for developing exertional heat stroke are unclear but acclimation may be an important countermeasure to protect health and performance.

What are the findings?

- Skin temperature, its rate of decrease and the core-to-skin temperature gradient (but not core temperature per se, $39.6 \pm 0.6^{\circ} \mathrm{C}$ ) were related to did not finish (DNF) or an in-race medical event.

- Nine per cent of surveyed athletes had diarrhoea in the 10 days preceding the World Athletics Championships, increasing their likelihood of DNF (from $20 \%$ to $43 \%$ ) and an in-race medical event (from $17 \%$ to $71 \%$ ).

- Sixty-three per cent of athletes had a dedicated heat acclimation of 5-30 days.

- They were better ranked, less likely to DNF or have an in-race medical event, alongside having lower thermal strain than the other athletes.

How might it impact on clinical practice in the future?

- Real-time measuring technologies under development should integrate skin temperature monitoring.

- Health status during the 10 days preceding a competition in the heat should be closely monitored, with a particular attention to diarrhoea.

- Educational materials on heat acclimation should be promoted to assist athlete preparation for hot weather events. 
flow to maintain a given level of heat dissipation. ${ }^{28}$ Importantly, the current WC road-races were contested at night and further studies remain necessary with different thermal loads.

\section{Limitations}

The current data represent a snapshot of the 2019 WC, held late in the season, during a pre-Olympic year and at night. Variations in events, period or time may lead to slightly different observations. Given the 'real-world' observations performed, not all athletes provided all information and they were free to follow their usual routines without any restrictions imposed by the research team. Therefore, values such as skin temperature may have been affected by the different cooling strategies of the athletes. Future studies should obtain nuanced detail behind DNF and medical events. The results from previous WC are presented only for context and complete retrospective analyses of the relationships between weather, health and/or performance are available elsewhere. ${ }^{29}$

\section{Conclusion}

The present study is the first to determine the association between athletes' thermal responses, preparation, health status, medical events and performance during a 'real-world' elite sporting event held in a hot-humid environment. Heat acclimation is increasingly practised and demonstrates various 'real-world' benefits for elite athletes competing in the heat. However, the prevalence of precompetition illnesses is concerning and a recent diarrhoea episode was markedly associated with an in-race medical event. Our results also challenge some current beliefs and practices such as considering $\mathrm{T}_{\text {core }}$ 'only'. $\mathrm{T}_{\text {skin }}$ and $\mathrm{T}_{\text {core }}$-to- $\mathrm{T}_{\text {skin }}$ gradient are shown here to be important indicators of the athlete's ability to cope with heat stress.

\section{Author affiliations}

Aspetar, Orthopaedic and Sports Medicine Hospital, FIFA Medical Centre of Excellence, Doha, Qatar

'Environmental Ergonomics Research Centre, Loughborough University, Loughborough, UK

${ }^{3}$ Human Potential Translational Research Program, Yong Loo Lin School of Medicine, National University of Singapore, Singapore

${ }^{4}$ School of Sport, Exercise and Health Sciences, Loughborough University, Loughborough, UK

${ }^{5}$ Human Performance Research Centre, University of Technology Sydney, Sydney, New South Wales, Australia

${ }^{6}$ Health and Science, World Athletics, Monaco

${ }^{7}$ LAMHESS, Université Côte d'Azur, Nice, France

${ }^{8}$ Inserm CIC1410, CHU Reunion, La Réunion, Réunion

${ }^{9}$ Interuniversity Laboratory of Human Movement Biology-EA 7424, Université Jean Monnet Saint-Etienne, Saint-Etienne, France

${ }^{10}$ Olympic Training and Service Centre Lower Saxony, Hannover, Germany

${ }^{11}$ Institute of Sport Exercise and Health (ISEH), University College London, London, UK

${ }^{12}$ High Performance Unit, Irish Rugby Football Union, Dublin, Ireland

${ }^{13} \mathrm{~S}$ chool of Sport Exercise and Health Sciences, Loughborough, UK

${ }^{14}$ Institute of Sport and Exercise Medicine, Stellenbosch University Faculty of Medicine and Health Sciences, Cape Town, South Africa

${ }^{15}$ Section Sports Medicine, University of Pretoria Faculty of Health Sciences, Pretoria, South Africa

${ }^{16}$ Unicaen, Inserm, Comete, GIP Cyceron, Normandie Universite, Caen, France

${ }^{17}$ Physical Education Department, College of Education, Qatar University, Doha, Qatar

${ }^{18}$ College of Health and Life Sciences, Hamad Bin Khalifa University, Doha, Qatar

Twitter Sebastien Racinais @ephysiol, Mohammed Ihsan @Ihsan_mo, Paolo Emilio Adami @paolo_emilio, Juan Manuel Alonso @DrJuanMAlonso, Marco Cardinale @Marco_Cardinale, Nicol van Dyk @NicolvanDyk, Chris JEsh @chris_esh, Josu Gomez-Ezeiza@goipergormance, Louis Holtzhausen @Louidoc and Nathan Townsend @DrNathanT
Acknowledgements The authors thank the World Athletics Health and Science Department for their endorsement, financial and operational support. The authors thank the local organising committee for their operational support.

Contributors SR designed the study and is responsible for the overall content as guarantor. All authors contributed to data collection and/or analyses. All authors revised the manuscript and approved the final version.

Funding This study was supported by World Athletics (formerly International Association of Athletics Federations).

Competing interests None declared.

Patient consent for publication Not applicable.

Ethics approval The study was approved by the Anti-Doping Lab Qatar Institutional Review Board (E2019000302) and conformed to the current Declaration of Helsinki guidelines. Participants gave informed consent to participate in the study before taking part.

Provenance and peer review Not commissioned; externally peer reviewed.

Data availability statement Data are available on reasonable request.

Supplemental material This content has been supplied by the author(s). It has not been vetted by BMJ Publishing Group Limited (BMJ) and may not have been peer-reviewed. Any opinions or recommendations discussed are solely those of the author(s) and are not endorsed by BMJ. BMJ disclaims all liability and responsibility arising from any reliance placed on the content. Where the content includes any translated material, BMJ does not warrant the accuracy and reliability of the translations (including but not limited to local regulations, clinical guidelines, terminology, drug names and drug dosages), and is not responsible for any error and/or omissions arising from translation and adaptation or otherwise.

Open access This is an open access article distributed in accordance with the Creative Commons Attribution Non Commercial (CC BY-NC 4.0) license, which permits others to distribute, remix, adapt, build upon this work non-commercially, and license their derivative works on different terms, provided the original work is properly cited, appropriate credit is given, any changes made indicated, and the use is non-commercial. See: http://creativecommons.org/licenses/by-nc/4.0/.

\section{ORCID iDs}

Sebastien Racinais http://orcid.org/0000-0003-0348-4744

Mohammed Ihsan http://orcid.org/0000-0001-5592-6888

Lee Taylor http://orcid.org/0000-0002-8483-7187

Paolo Emilio Adami http://orcid.org/0000-0001-5975-5342

Maria-Carmen Adamuz http://orcid.org/0000-0002-8019-193X

Juan Manuel Alonso http://orcid.org/0000-0003-1350-8746

Marco Cardinale http://orcid.org/0000-0002-2777-8707

Nicol van Dyk http://orcid.org/0000-0002-0724-5997

Josu Gomez-Ezeiza http://orcid.org/0000-0003-0437-2226

Louis Holtzhausen http://orcid.org/0000-0002-4002-8679

Khouloud Mtibaa http://orcid.org/0000-0001-7522-6125

Mathew G Wilson http://orcid.org/0000-0002-6317-0168

Stephane Bermon http://orcid.org/0000-0002-9529-2901

\section{REFERENCES}

1 Ely MR, Cheuvront SN, Roberts WO, et al. Impact of weather on marathon-running performance. Med Sci Sports Exerc 2007;39:487-93.

2 Hollander K, Klöwer M, Richardson A, et al. Apparent temperature and heat-related illnesses during international athletic championships: a prospective cohort study. Scand J Med Sci Sports 2021;31:2092-102.

3 Hosokawa Y, Racinais S, Akama T. Prehospital management of exertional heat stroke at sports competitions: international Olympic Committee adverse weather impact expert Working group for the Olympic Games Tokyo. British Journal of Sports Medicine 2020.

4 Byrne C, Lee JKW, Chew SAN, et al. Continuous thermoregulatory responses to massparticipation distance running in heat. Med Sci Sports Exerc 2006;38:803-10.

5 Racinais S, Moussay S, Nichols D, et al. Core temperature up to $41.5^{\circ} \mathrm{C}$ during the UCl road cycling world Championships in the heat. Br J Sports Med 2019;53:426-9.

6 Racinais S, Alhammoud M, Nasir N, et al. Epidemiology and risk factors for heat illness: 11 years of heat stress monitoring programme data from the FIVB beach Volleyball world tour. Br J Sports Med 2021;55:831-5.

7 Yankelson L, Sadeh B, Gershovitz L, et al. Life-threatening events during endurance sports: is heat stroke more prevalent than arrhythmic death? J Am Coll Cardiol 2014;64:463-9.

8 Stearns RL, Casa DJ, O'Connor F. Exertional heat stroke. In: preventing sudden death in sport and physical activity. Burlington: Jones \& Bartlett Learning, 2017: 71-96.

9 Hosokawa Y, Stearns RL, Casa DJ. Is heat intolerance state or trait? Sports Med 2019;49:365-70.

10 Racinais S, Alonso JM, Coutts AJ, et al. Consensus recommendations on training and competing in the heat. Br J Sports Med 2015;49:1164-73. 
11 Tyler CJ, Reeve T, Hodges GJ, et al. The effects of heat adaptation on physiology, perception and exercise performance in the heat: a meta-analysis. Sports Med 2016;46:1699-724.

12 Périard JD, Racinais S, Timpka T, et al. Strategies and factors associated with preparing for competing in the heat: a cohort study at the 2015 IAAF world athletics Championships. Br J Sports Med 2017;51:264-70.

13 Racinais S, Nichols D, Travers G, et al. Health status, heat preparation strategies and medical events among elite cyclists who competed in the heat at the $2016 \mathrm{UCl}$ road world cycling Championships in Qatar. Br J Sports Med 2020;54:1003-7.

14 Aylwin PE, Racinais S, Bermon S, et al. The use of infrared thermography for the dynamic measurement of skin temperature of moving athletes during competition; methodological issues. Physiol Meas 2021;42. doi:10.1088/1361-6579/ac1872. [Epub ahead of print: 2708 2021].

15 Racinais S, Ihsan M, Taylor L, et al. Hydration and cooling in elite athletes: relationship with performance, body mass loss and body temperatures during the Doha 2019 IAAF world athletics Championships. Br J Sports Med 2021:55:1335-41.

16 Schwellnus MP. Cause of exercise associated muscle cramps (EAMC)--altered neuromuscular control, dehydration or electrolyte depletion? Br J Sports Med 2009;43:401-8.

17 Stevens CJ, Ross ML, Périard JD, et al. Core temperature responses to elite Racewalking competition. Int J Sports Physiol Perform 2020;15:892-5.

18 Gagnon D, Kenny GP. Does sex have an independent effect on thermoeffector responses during exercise in the heat? J Physiol 2012;590:5963-73.

19 Notley SR, Park J, Tagami K, et al. Variations in body morphology explain sex differences in thermoeffector function during compensable heat stress. Exp Physiol 2017; 102:545-62.

20 Foster J, Hodder SG, Lloyd AB, et al. Individual responses to heat stress: implications for hyperthermia and physical work capacity. Front Physiol 2020;11:541483.
21 Notley SR, Racinais S, Kenny GP. Do sex differences in thermoregulation pose a concern for female athletes preparing for the Tokyo Olympics? Br J Sports Med 2021;55:298-9.

22 Racinais S, Périard JD, Karlsen A, et al. Effect of heat and heat acclimatization on cycling time trial performance and pacing. Med Sci Sports Exerc 2015;47:601-6.

23 Timpka T, Jacobsson J, Bargoria V, et al. Preparticipation predictors for Championship injury and illness: cohort study at the Beijing 2015 international association of athletics Federations world Championships. Br J Sports Med 2017;51:271-6.

24 Van Tonder A, Schwellnus M, Swanevelder S, et al. A prospective cohort study of 7031 distance runners shows that 1 in 13 report systemic symptoms of an acute illness in the 8-12 day period before a race, increasing their risk of not finishing the race 1.9 times for those runners who started the race: SAFER study IV. Br J Sports Med 2016;50:939-45.

25 Bennett CJ, Henry R, Snipe RMJ, et al. Is the gut microbiota bacterial abundance and composition associated with intestinal epithelial injury, systemic inflammatory profile, and gastrointestinal symptoms in response to exertional-heat stress? I Sci Med Sport 2020;23:1141-53.

26 Périard JD, Racinais S, Sawka MN. Adaptations and mechanisms of human heat acclimation: applications for competitive athletes and sports. Scand J Med Sci Sports 2015;25 Suppl 1:20-38

27 Cuddy JS, Hailes WS, Ruby BC. A reduced core to skin temperature gradient, not a critical core temperature, affects aerobic capacity in the heat. J Therm Biol 2014;43:7-12.

28 Kenefick RW, Cheuvront SN, Sawka MN. Thermoregulatory function during the marathon. Sports Med 2007;37:312-5.

29 Mantzios K, loannou LG, Panagiotaki Z, et al. Effects of weather parameters on endurance running performance: discipline specific analysis of 1258 races. Med Sci Sports Exerc 2022;54:153-61.

30 Allen M, Poggiali D, Whitaker K, et al. Raincloud plots: a multi-platform tool for robust data visualization. Wellcome Open Res 2019;4:63. 